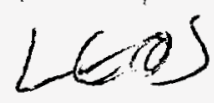

$$
\begin{array}{r}
59 N 098-1526 C \\
\text { SAND- }-98-1526 C
\end{array}
$$

Vertical cavity surface emitting laser emitting at 1.56 microns with AlGaAsSb/AlAsSb distributed Bragg reflectors

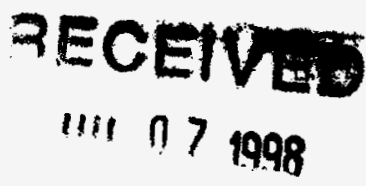

We report $77 \mathrm{~K}$ operation of an optically pumped vertical cavity surface emitting laser with an Sb-based cavity. The structure consists of 15 and 20 pair AlGaAsSb/AlAsSb top and bottom reflectors and a bulk InGaAs active region. 


\section{DISCLAIMER}

This report was prepared as an account of work sponsored by an agency of the United States Government. Neither the United States Government nor any agency thereof, nor any of their employees, makes any warranty, express or implied, or assumes any legal liability or responsibility for the accuracy, completeness, or usefulness of any information, apparatus, product, or process disclosed, or represents that its use would not infringe privately owned rights. Reference herein to any specific commercial product, process, or service by trade name, trademark, manufacturer, or otherwise does not necessarily constitute or imply its endorsement, recom. mendation, or favoring by the United States Government or any agency thereof. The views and opinions of authors expressed herein do not necessarily state or reflect those of the United States Government or any agency thereof. 


\section{DISCLAIMER}

Portions of this document may be illegible electronic image products. Images are produced from the best available original document. 


\title{
Vertical cavity surface emitting laser emitting at 1.56 microns with AlGaAsSb/AlAsSb distributed Bragg reflectors
}

\author{
O. Blum, J. F. Klem, K. L. Lear, G. A. Vawter, S. R. Kurtz \\ Sandia National Laboratories, P. O. Box 0603, Albuquerque, NM 87185
}

Long-wavelength vertical cavity surface emitting lasers (VCSELs) are attractive for a variety of application, such as low cost sources for optical communications and optical interconnects. One of the major obstacles to implementing these structures has been the lack of sufficiently large refractive index contrast $(\Delta n)$ in the mirror layer pairs that can be lattice matched to InP. There are a variety of epitaxial approaches to this problem, from wafer bonding GaAs/AlAs DBRs $(\Delta \mathrm{n} \sim 0.44)$ to growing very thick $\mathrm{InP} / \mathrm{InGaAsP}$ DBRs $(\Delta \mathrm{n} \sim 0.31)$. In order to realize a monolithic device, we have utilized a $\mathrm{AlGaAsSb} / \mathrm{AlAsSb}$ material system $(\Delta \mathrm{n} \sim \theta .52)$ lattice matched to InP as a means of forming highly reflecting distributed Bragg reflectors (DBRs) with relatively few mirror pairs. The structure was grown by molecular beam epitaxy. The active region consists of $2 \lambda$ thick bulk InGaAs, whereas top and bottom DBR are made up of 15 and 20 periods of $\mathrm{AlGaAsSb} / \mathrm{AlAsSb}$ mirror pairs, respectively. This corresponds to an active region of 878 $\mathrm{nm}$ with $135 \mathrm{~nm}$ and $117 \mathrm{~nm}$ thick low and high refractive index layers, respectively. The device structure is shown in Fig. 1. The high refractive index layers, $\mathrm{AlGaAsSb}$ contain $12 \% \mathrm{Al}$, in order to make them transparent at the emission wavelength. We found that at $77 \mathrm{~K}$ their absorption edge occurs at $1.3 \mu \mathrm{m}$. In a separate structure, $77 \mathrm{~K}$ reflectivity of the 15 pair DBR was measured to be $>99 \%$ in good agreement with a calculated value of $99.2 \%$. Calculations indicate that the 20 pair DBR reflects $99.8 \%$ of incident light.

Fig. 2 shows the below and above threshold spectra of the VCSEL. Lasing peak occurs at $1564 \mathrm{~nm}$ with $0.2 \mathrm{~nm}$ linewidth. Below threshold, linewidth is measured to be approximately $2.5 \mathrm{~nm}$ and occurs at $1568 \mathrm{~nm}$. This agrees well with the calculated width of the Fabry-Perot resonance. The structure was pumped $\mathrm{CW}$ by a $1.32 \mu \mathrm{m}$ diode pumped Nd:YAG through a single mode fiber. Power was coupled through one of the input legs of a $2 \mathrm{X} 210 / 90$ fiber splitter, with one output leg of the splitter in physical contact with the sample, which was submerged in liquid nitrogen. The other output leg was used to monitor the incident power, whereas the second input leg was connected to the optical spectrum analyzer for spectral measurements or a power meter for $\mathrm{L}-\mathrm{L}$ measurements. Spot size on the sample was taken to be equal to the core of the single mode fiber, $9 \mu \mathrm{m}$. Results of the light in-light out (L-L) measurement are shown in Fig. 3. Threshold occurs at $44 \mathrm{mw}$. This corresponds to incident power density of $69 \mathrm{~kW} / \mathrm{cm}^{2}$ and equivalent current density of $32 \mathrm{kA} / \mathrm{cm}^{2}$. Since the pump wavelength falls outside of the FabryPerot stop band we assume single pass configuration of the pump with $75 \%$ of the incident power transmitted through the top mirror. Absorption coefficient of the active region is taken to be $1 \mu \mathrm{m}^{-1}$. Such equivalent current densities are comparable to results obtained with optically pumped InP/InGaAsP DBRs or GaAs/AlAs bonded DBR results. This represents the first report of stimulated emission in a Sb-based cavity, lattice matched to InP. The results are comparable to other approaches involving optical pumping and similar active regions, in spite of a $\mathrm{CW}$ pump source 


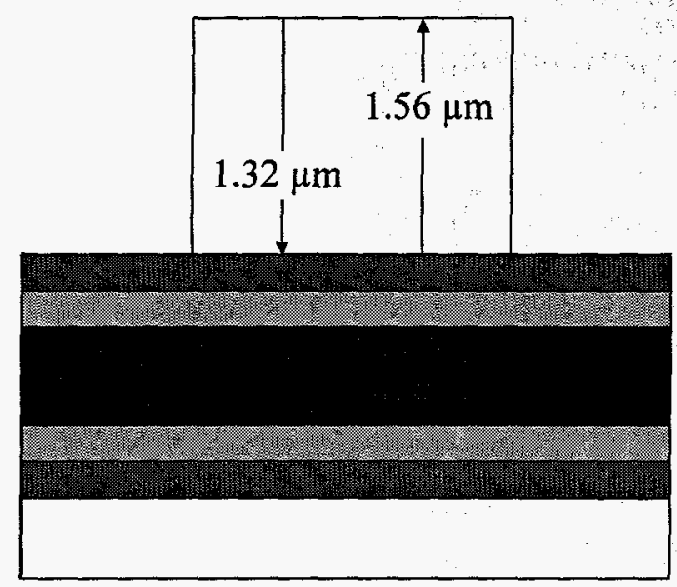

15 period DBR -

AlGaAsSb/AlAsSb

InGaAs

20 period DBR -

AlGaAsSb/AlAsSb

InP

Fig. 1 Schematic diagram of the VCSEL with AlGaAsSb/AlAsSb.DBRs.

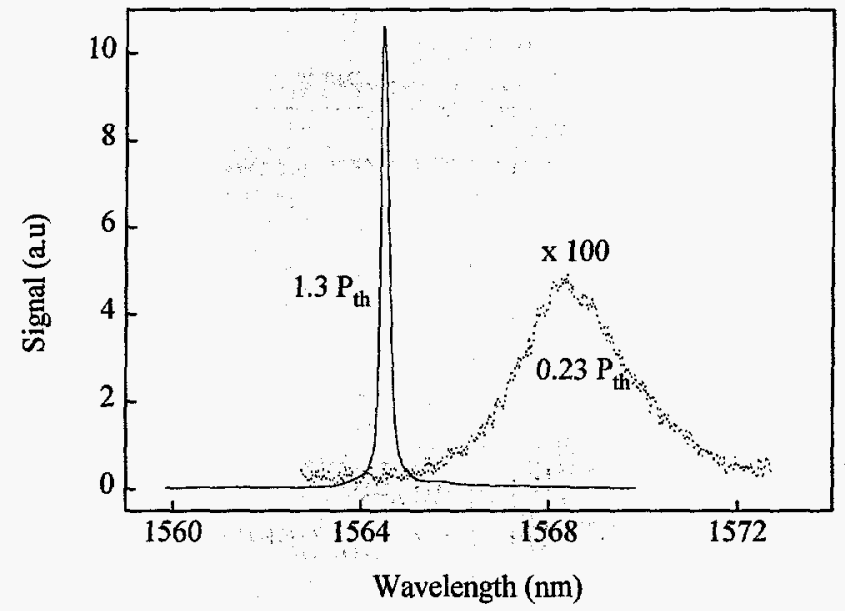

Fig. 2 Below and above threshold spectra

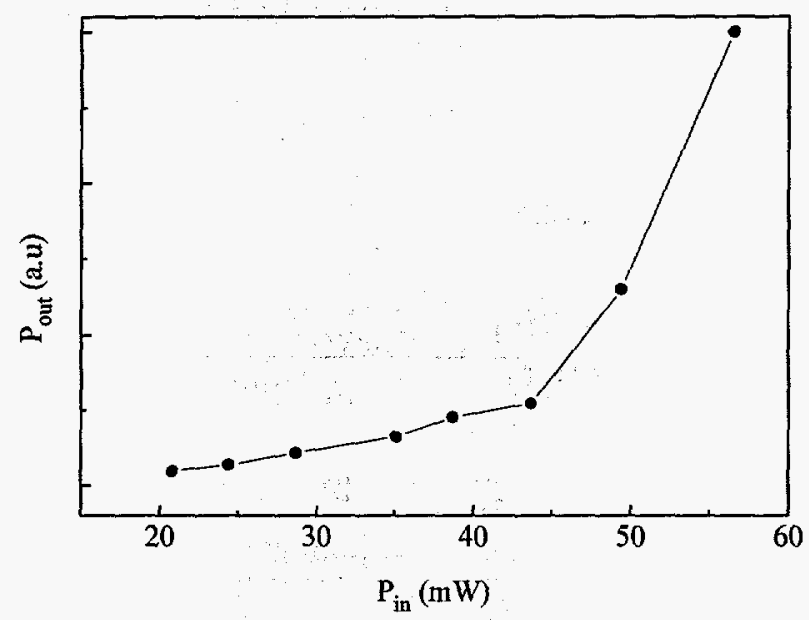

Fig. 3 Output power versus input pump power 